\title{
Tissue Distribution and Induction of Human Multidrug Resistant Protein 3
}

\author{
George L. Scheffer, Marcel Kool, Marcel de Haas, J. Marleen L. de Vree, \\ Adriana C. L. M. Pijnenborg, Diederik K. Bosman, Ronald P. J. Oude Elferink, \\ Paul van der Valk, Piet Borst, and Rik J. Scheper
}

\author{
Department of Pathology (GLS, ACLMP, PvdV, RJS), Free University Medical Center; Department of Neurology (MK), \\ Academic Medical Center; Division of Molecular Biology and Center of Biomedical Genetics (MdH, PB), The Netherlands \\ Cancer Institute; Department of Gastroenterology and Liver Diseases (JMLdV, RPJOE), Academic Medical Center; and \\ Department of Experimental Internal Medicine (DKB), Academic Medical Center, Amsterdam, The Netherlands
}

\begin{abstract}
SUMMARY: The multidrug resistance protein (MRP) family consists of several members and, for some of these transporter proteins, distinct roles in multidrug resistance and normal tissue functions have been well established (MRP1 and MRP2) or are still under investigation (MRP3). MRP3 expression studies in human tissues have been largely restricted to the mRNA level. In this report we extended these studies and further explored MRP3 expression at the protein level. Western blot and immunohistochemistry with two MRP3-specific monoclonal antibodies, $\mathrm{M}_{3} \mathrm{ll}-9$ and $\mathrm{M}_{3} \mathrm{ll}-21$, showed MRP3 protein to be present in adrenal gland, and kidney and in tissues of the intestinal tract: colon, pancreas, gallbladder, and liver. In epithelia, MRP3 was found to be located at the basolateral sides of cell membranes. In normal liver, MRP3 was detected at lower levels than anticipated from the mRNA data and was found present mainly in the bile ducts. In livers from patients with various forms of cholestasis, MRP3 levels were frequently increased in the proliferative cholangiocytes, with sometimes additional staining of the basolateral membranes of the hepatocytes. This was especially evident in patients with type 3 progressive familial intrahepatic cholestasis. The present results support the view that MRP3 plays a role in the cholehepatic and enterohepatic circulation of bile and in protection within the biliary tree and tissues along the bile circulation route against toxic bile constituents. The possible functional roles for MRP3 in the adrenal gland and in the kidney remain as yet unknown. In a panel of 34 tumor samples of various histogenetic origins, distinct amounts of MRP3 were detected in a limited number of cases, including lung, ovarian, and pancreatic cancers. These findings may be of potential clinical relevance when considering the drug treatment regimens for these tumor types. (Lab Invest 2002, 82:193-201).
\end{abstract}

$A$ $t$ least seven members of the multidrug resistance protein (MRP) subfamily of ATP binding cassette (ABC) transporters, called MRP1-7, have been identified in humans (Borst et al, 2000; Hopper et al, 2001; Kool et al, 1997). Until recently, only MRP1 and MRP2 were shown to confer resistance to a wide variety of chemotherapeutic agents in human cancer cells (Cole and Deeley, 1998; Cole et al, 1992; Cui et al, 1999; Evers et al, 2000). MRP1 and MRP2 transport these compounds either conjugated to anionic ligands such as glutathione, glucuronate, or sulfate, or unmodified along with glutathione. MRP1 and MRP2 are therefore also called GS-X pumps. MRP3, the closest relative of MRP1 among MRP family members (58\% amino acid identity), is also a GS-X pump as demonstrated ex-

Received October 30, 2001.

The first two authors contributed equally to this study. This work was supported in part by Koningin Wilhelmina Fonds grant VU 96-1256 (to RJS), grants NKI 94-775, NKI 95-963, and NKI 98-1794 (to PB), Nederlandse Organisatie voor Wetenschappelijk Onderzoek grant 902-23097 (to PB and ROE) and the Netherlands Asthma Foundation grant AF 97.35 (to RJS).

Address reprint requests to: Prof. R. J. Scheper, Free University Medical Center, Department of Pathology, De Boelelaan 1117, 1081 HV Amsterdam, The Netherlands.E-mail: rj.scheper@vumc.nl perimentally by transport of $S$-(2, 4-dinitrophenyl)glutathione (Kool et al, 1999). In MRP3 transfected cell lines, the range of drugs to which resistance has been observed is rather limited compared with MRP1 and MRP2 (Zeng et al, 1999). In continuous exposure experiments, only resistance to etoposide and teniposide was found, but not to other drugs (Kool et al, 1999). However, in a panel of lung cancer cell lines, associations between MRP3 expression and resistance were observed, not only to etoposide, but also to doxorubicin, vincristine, and cisplatin (Young et al, 1999). Moreover, using short-term exposures, cells overproducing MRP3 were found to be highly resistant to methotrexate (MTX) (Kool et al, 1999), in line with the observation in vesicular transport experiments that rat Mrp3 can transport MTX (Hirohashi et al, 1999). In such experiments, rat Mrp3 was also found to prefer glucuronide conjugates over glutathione conjugates and to be capable of transporting bile salts, including glycocholate, taurocholate, and taurolithocholate-3sulfate (Hirohashi et al, 2000). Also for human MRP3, transport of glycocholate at low affinity but with high capacity was reported (Zeng et al, 2000).

Not much is known about the physiologic function of MRP3 in normal human tissues. MRP3 mRNA is readily detectable in adrenal gland, colon, small intes- 
tine, pancreas, liver, and, generally at lower levels, in kidney and lung (Belinsky et al, 1998; Kiuchi et al, 1998; Konig et al, 1999; Kool et al, 1997; Uchiumi et al, 1998) (see Table 1). In normal rat liver, Mrp3 mRNA expression is very low, but in Eisai hyperbilirubinemic (EHBR) and in $\mathrm{TR}^{-}$mutant rats, as well as in normal rats with ligated bile ducts, expression of Mrp3 is strongly increased (Hirohashi et al, 1998; Ortiz et al, 1999; Soroka et al, 2001). Also in Dubin-Johnson patients, who lack MRP2 in liver canalicular membranes, polyclonal anti-MRP3 antisera showed high levels of MRP3 in the hepatocytes (Konig et al, 1999). Normal human livers show only low levels of MRP3 protein, mainly limited to the basolateral membranes of bile duct epithelial cells and hepatocytes surrounding the portal tracts (Kool et al, 1999). The function of MRP3 in these and other cells is still unknown, but the available information suggests a role of MRP3 in the efflux of organic anions from the liver into the blood under conditions when secretion into bile is blocked.

In this article, we present our studies on the presence and cellular localization of MRP3 in an extended panel of normal human tissues, as well as in human livers of several cholestatic patients and in human tumor samples.

\section{Results}

\section{MRP3 in Membrane Fractions of Normal Human Tissues}

Using Western blots, the anti-MRP3 Mab readily detected MRP3 in membrane fractions of normal human tissues (Fig. 1). In adrenal gland and kidney, considerable amounts of MRP3 were detected. In liver, MRP3 levels were generally low, but sometimes relatively high MRP3 levels were observed. Furthermore, in pancreas, gallbladder, colon, duodenum, and ileum MRP3 was detected, whereas in stomach and spleen MRP3 was very low or undetectable. Invariably, in all positive tissues, the MRP3 protein was detected as doublet bands of slightly variable molecular weights. Most likely, these bands represent differently glycosylated forms of MRP3, as observed earlier with samples derived from tumor cell lines (Kool et al, 1999).

\section{Immunolocalization of MRP3 in Human Tissues}

In frozen sections of normal human tissues, distinct MRP3 staining was detected in the adrenal gland, pancreas, gallbladder, colon, kidney, and liver (Figs. 2, 3, and 4). In the other tissues examined, including lung, stomach, spleen, tonsil, breast, salivary gland, thyroid, testis, ovary, bladder, skeletal muscle, heart, brain, cerebellum, and placenta, no MRP3 was detected.

\section{Adrenal Gland}

High levels of MRP3 were detected in the cortex only; in the medulla, MRP3 staining was absent. In the cortex, MRP3 staining was restricted to the cells of the zona fasciculata and the zona reticularis; no staining of the cells in the outermost zona glomerulosa was observed (Fig. 2a). This staining pattern is markedly different from the staining patterns observed with the

Table 1. Reported MRP3 mRNA Levels in Normal Human Tissues

\begin{tabular}{|c|c|c|c|c|c|}
\hline $\begin{array}{l}\text { Human tissue } \\
\text { type }\end{array}$ & Kool et al, 1997 & Kiuchi et al, 1998 & Uchiumi et al, 1998 & Belinsky et al, 1998 & Konig et al, 1999 \\
\hline Adrenal gland & +++ & n.t. & n.t. & n.t. & n.t. \\
\hline Colon & +++ & +++ & + & +++ & ++ \\
\hline Small intestine & +++ & +++ & + & + & - \\
\hline Liver & ++++ & +++ & +++ & ++ & ++ \\
\hline Kidney & + & + & - & + & $+1-$ \\
\hline Pancreas & + & n.t. & - & ++ & ++ \\
\hline Lung & + & + & - & $+/-$ & - \\
\hline Stomach & + & n.t. & n.t. & n.t. & n.t. \\
\hline Spleen & + & + & - & - & - \\
\hline Tonsil & + & n.t. & n.t. & n.t. & n.t. \\
\hline Mammary gland & - & n.t. & n.t. & n.t. & n.t. \\
\hline Salivary gland & - & n.t. & n.t. & n.t. & n.t. \\
\hline Thyroid & - & n.t. & n.t. & n.t. & n.t. \\
\hline Testis & - & - & - & - & - \\
\hline Ovary & - & - & - & - & - \\
\hline Nerve & - & n.t. & n.t. & n.t. & n.t. \\
\hline Bladder & + & n.t. & n.t. & n.t. & n.t. \\
\hline Skeletal muscle & - & - & - & - & - \\
\hline Heart & - & - & - & - & - \\
\hline Brain & - & - & - & - & - \\
\hline Placenta & - & $+1-$ & - & + & - \\
\hline Thymus & n.t. & - & - & - & - \\
\hline Prostate & n.t. & $+1-$ & + & $+1-$ & - \\
\hline
\end{tabular}

n.t., not tested; -, no expression; $+/-$, very weak; + , weak; ++ , moderate; +++ , strong; ++++ , very strong expression. 
a

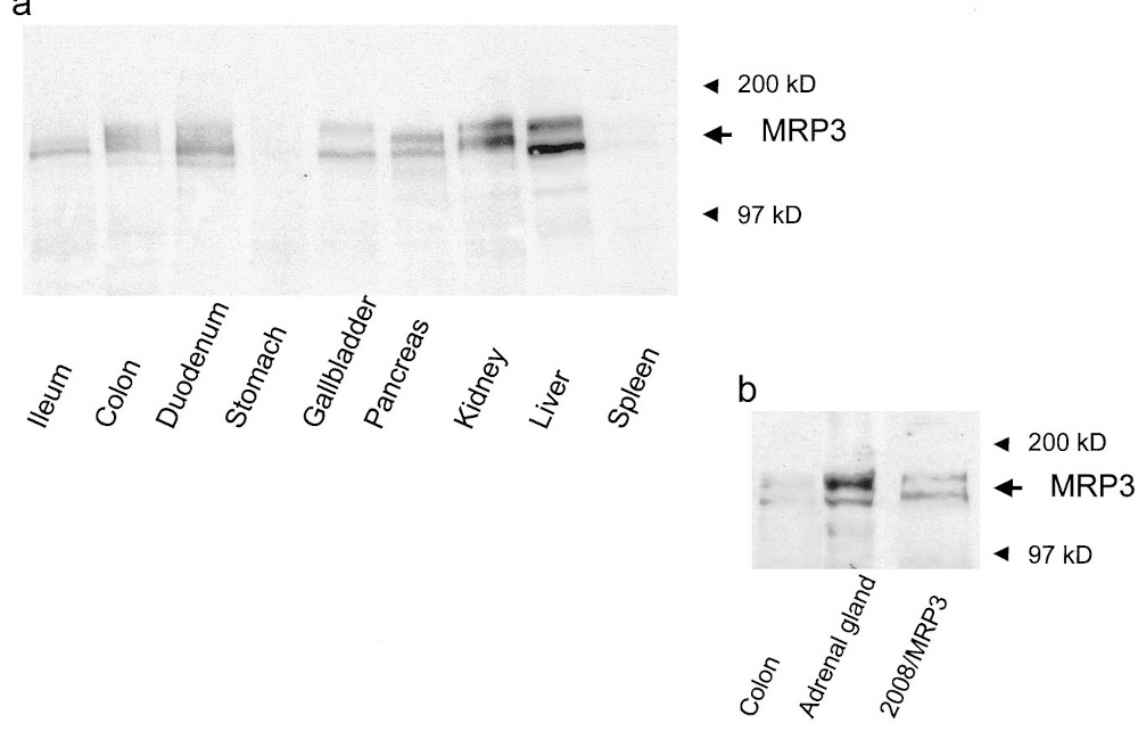

Figure 1.

Western blot detection of multidrug resistance protein (MRP) 3 protein in membrane fractions derived from normal human tissues (a and b). In b, adrenal gland and colon are shown from another, but essentially identical, Western blot experiment. As a positive control, a protein sample of MRP3-transfected 2008 ovarian carcinoma cells was loaded. MRP3 protein was visualized with monoclonal antibody $\mathrm{M}_{3} \mathrm{ll}-9$ and enhanced chemiluminescence. As observed earlier with tumor cell line-derived samples (Kool et al, 1999), differential glycosylation of MRP3 in human tissues results in doublet bands of slightly variable molecular weights.

anti-MDR1 P-glycoprotein (P-gp) Mab JSB-1 or C219: MDR1 $\mathrm{P}-\mathrm{gp}$ is detected in all three layers of the adrenal cortex (Fig. 2b).

\section{Pancreas}

Clear MRP3 staining was observed in the basolateral membranes of the epithelial cells of the ductules (Fig. 2d). In contrast, control stainings for MDR1 P-gp revealed the more apically oriented staining of the epithelial cells lining smaller, thinner ducts (Fig. 2e).

\section{Gallbladder}

High levels of MRP3 were observed in the epithelial cells. Again the staining was most prominent at the basolateral membranes (Fig. 3a).

\section{Colon}

As anticipated from the Western blotting results, considerable MRP3 staining was observed in colon tissue. Although background staining was high in this tissue, strongest staining was observed in the membranes of the crypt cells.

\section{Kidney}

MRP3 was absent from the glomeruli, the proximal convoluted tubules, and the collecting ducts, but clear staining was observed in the basolateral membranes of the distal convoluted tubules and, most likely, the thick ascending loops of Henle (Fig. 3c). The MRP3 staining pattern paralleled the staining observed with a polyclonal antiserum against the Tamm-Horsfall protein, known to be localized in the early distal convoluted tubules and the thick ascending loops of Henle
(Sikri et al, 1981) (Fig. 3d), but not with the staining for aquaporin-2, identifying the collecting ducts (Deen et al, 1995; Nielsen et al, 1993) (Fig. 3f). Control stainings for MRP2 identified the proximal tubuli (Fig. 3e).

\section{Liver}

Despite the high MRP3 mRNA levels that we and others observed in human liver (Belinsky et al, 1998; Kiuchi et al, 1998; Konig et al, 1999; Kool et al, 1997; Uchiumi et al, 1998) (Table 1) and the incidentally high levels observed in Western blots, immunohistochemical stainings showed only low levels of MRP3 protein in normal human livers. Confirming initial findings (Kool et al, 1999), the MRP3 staining was mainly restricted to the cholangiocytes of the bile ducts, with sometimes weak additional staining in the basolateral membranes of surrounding hepatocytes (Fig. 4a).

\section{Cholestatic Human Liver}

Because MRP3 protein levels might increase as a consequence of liver dysfunctioning (Hirohashi et al, 1998; Konig et al, 1999; Ortiz et al, 1999), we further analyzed human liver samples of patients with moderate to severe cholestasis. These patients included a hepatitis patient with mild cholestasis, a patient with obstructive cholestasis and bile duct proliferation due to a Klatskin tumor, three patients with biliary atresia who have cholestasis due to lack of bile ducts, and four patients who had been diagnosed with different types of progressive familial intrahepatic cholestasis (PFIC) with end-stage liver disease, showing severe cholestasis and bile duct proliferation (see "Materials and Methods"). Different levels and patterns of MRP3 expression were observed in these patients. 

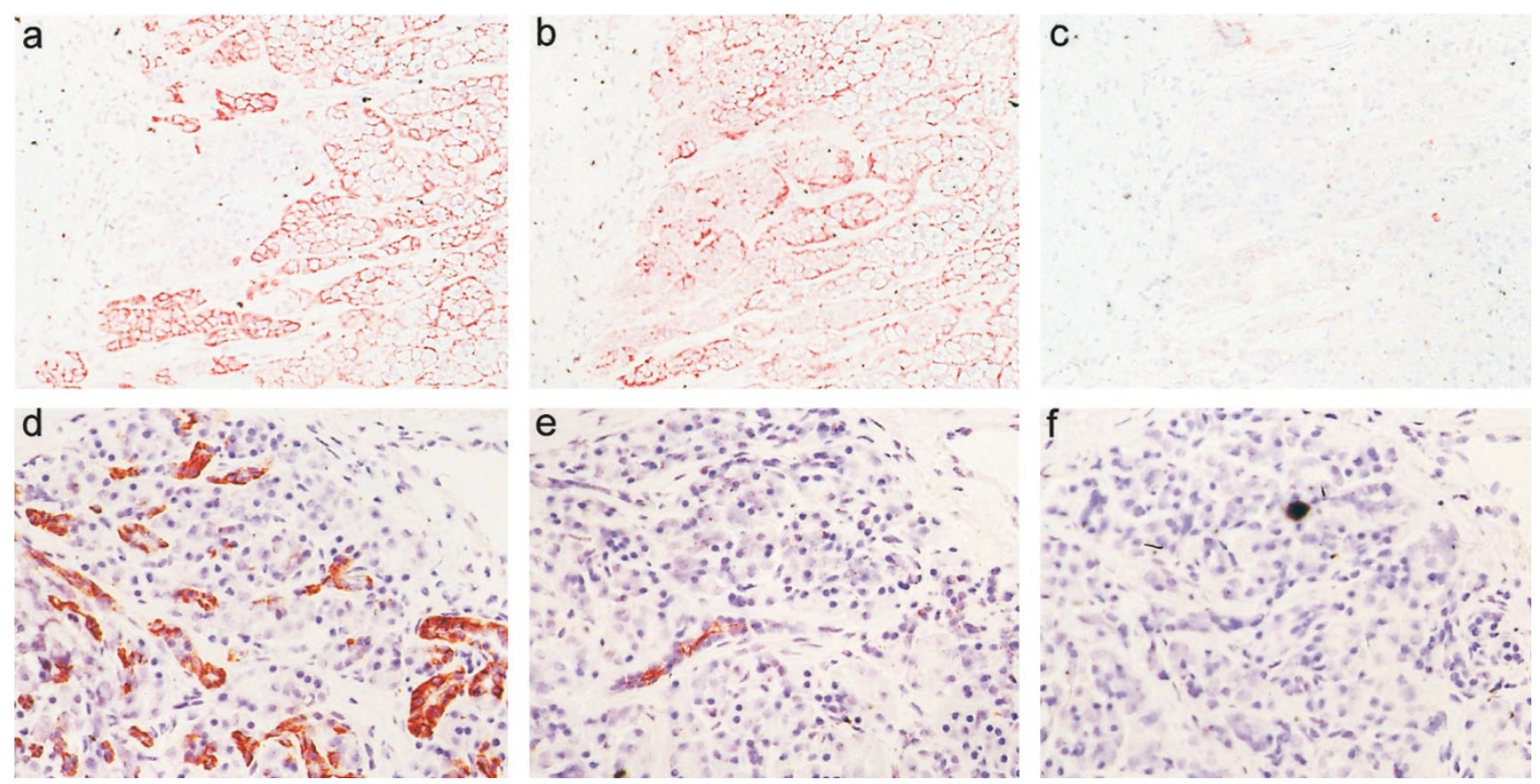

Figure 2.

Immunohistochemical detection of MRP3 and MDR1 P-gp in adrenal gland (upper panel) and pancreas (lower panel) using aminoethyl carbazole as the chromogen. MRP3 was stained with $\mathrm{M}_{3} \mathrm{Il}-9$ ( $a$ and $d$ ) and MDR1 P-gp with C219 monoclonal antibody (Mab) ( $b$ and e). Staining with the negative control antibody is shown in $\mathrm{c}$ and f. MRP3 is present in the adrenal cortex in the cells of the zona fasciculata and the zona reticularis. MDR1 P-gp is detected in all three layers of the adrenal cortex. In human pancreas, MRP3 staining is observed in the basolateral membranes of the epithelial cells of the ductules. Control stainings for MDR1 P-gp show a more apically oriented staining, in the epithelial cells of smaller, thinner ducts.

In the PFIC2 patient (Fig. 4c), and particularly in the patient with the Klatskin tumor (Fig. 4d), as well as in the PFIC1 patient (Fig. 4e), elevated MRP3 staining was observed within the proliferative bile duct epithelium, but no staining was observed in the hepatocytes.
In contrast, unchanged levels of bile duct MRP3 but moderately to highly increased levels of MRP3 in the hepatocytes were observed in two of three patients with biliary atresia (Fig. 4f, Patient B) and in the patient with hepatitis (Fig. 4g).
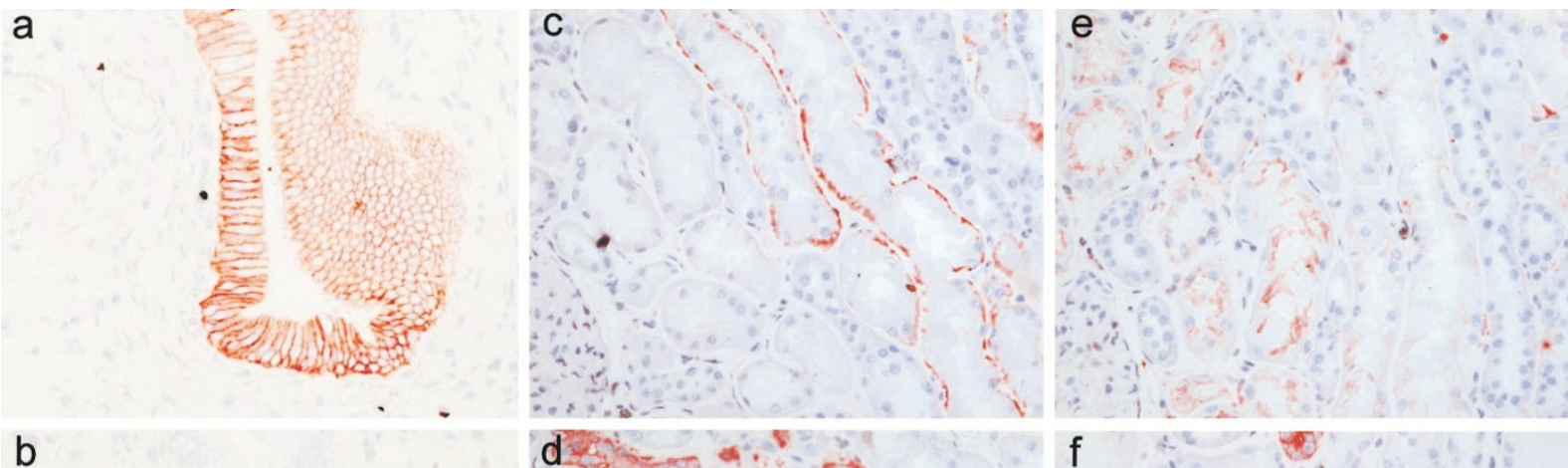

b
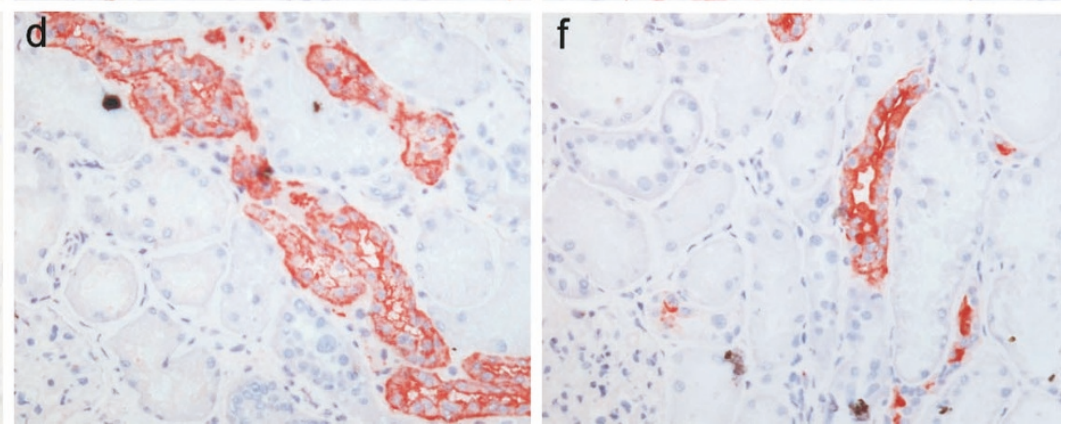

Figure 3.

Immunohistochemical detection of MRP3 in human gallbladder ( $a$ and $b$ ) and kidney ( $c$ to $f$ ) using aminoethyl carbazole as the chromogen. MRP3 was stained with $\mathrm{M}_{3}$ II-9. In gallbladder MRP3 staining is observed in the epithelial cells (a). Staining with the negative control antibody in gallbladder is shown in b. In kidney, MRP3 staining is observed in the basolateral membranes of the distal convoluted tubules and, possibly, the thick ascending loops of Henle (c). Positive control stainings for kidney are shown in d (rabbit polyclonal antiserum detecting Tamm-Horsfall protein in the early distal convoluted tubules and the thick ascending loops of Henle), e (MRP2, detected with $\mathrm{M}_{2}$ III-6 Mab in the proximal tubuli), and $\mathrm{f}$ (rabbit polyclonal antiserum detecting aquaporin-2 in the collecting ducts). 

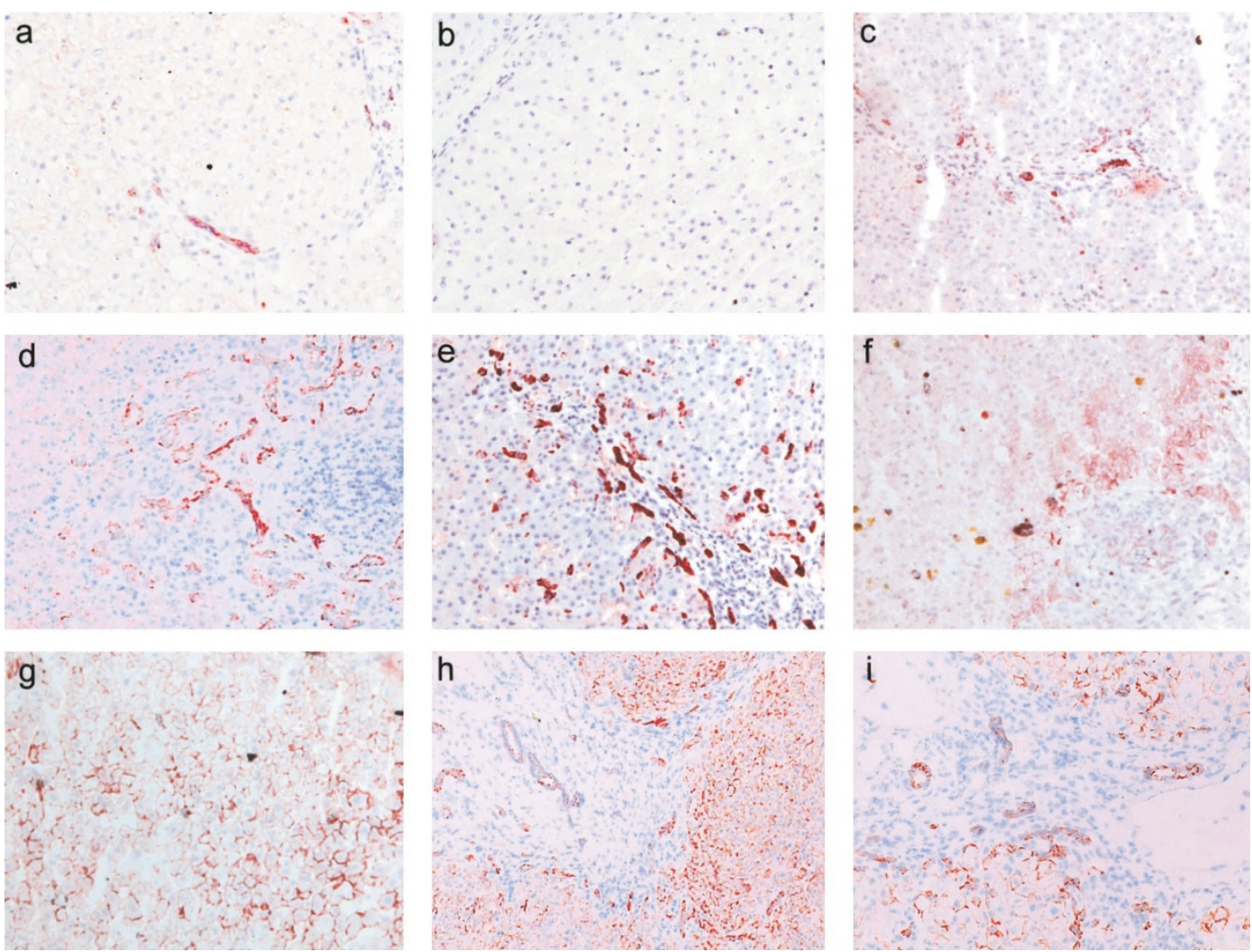

Figure 4.

Immunohistochemical detection of MRP3 with the $\mathrm{M}_{3} \mathrm{II}-9 \mathrm{Mab}$ in normal human liver and in livers from patients with bile duct obstruction. In normal human liver, generally low levels of MRP3 are detected, mainly at the bile ducts (a). The negative control Mab is shown in b. In the PFIC2 patient (c), and particularly in the patient with the Klatskin tumor (d), as well as in the PFIC1 patient (e), elevated MRP3 staining is observed within the proliferative bile duct epithelium, but no staining is seen in the hepatocytes. In contrast, unchanged levels of bile duct MRP3 but moderately to highly increased levels of MRP3 in the hepatocytes are observed in a patient with biliary atresia (f, Patient $B$ ) and in the hepatitis patient $(\mathrm{g})$. The highest MRP3 levels are observed in the two PFIC3 patients ( $h$, Patient D, and i, Patient E). In these livers, both bile ducts and almost all hepatocytes stain strongly positive for MRP3. For patient information see "Materials and Methods."
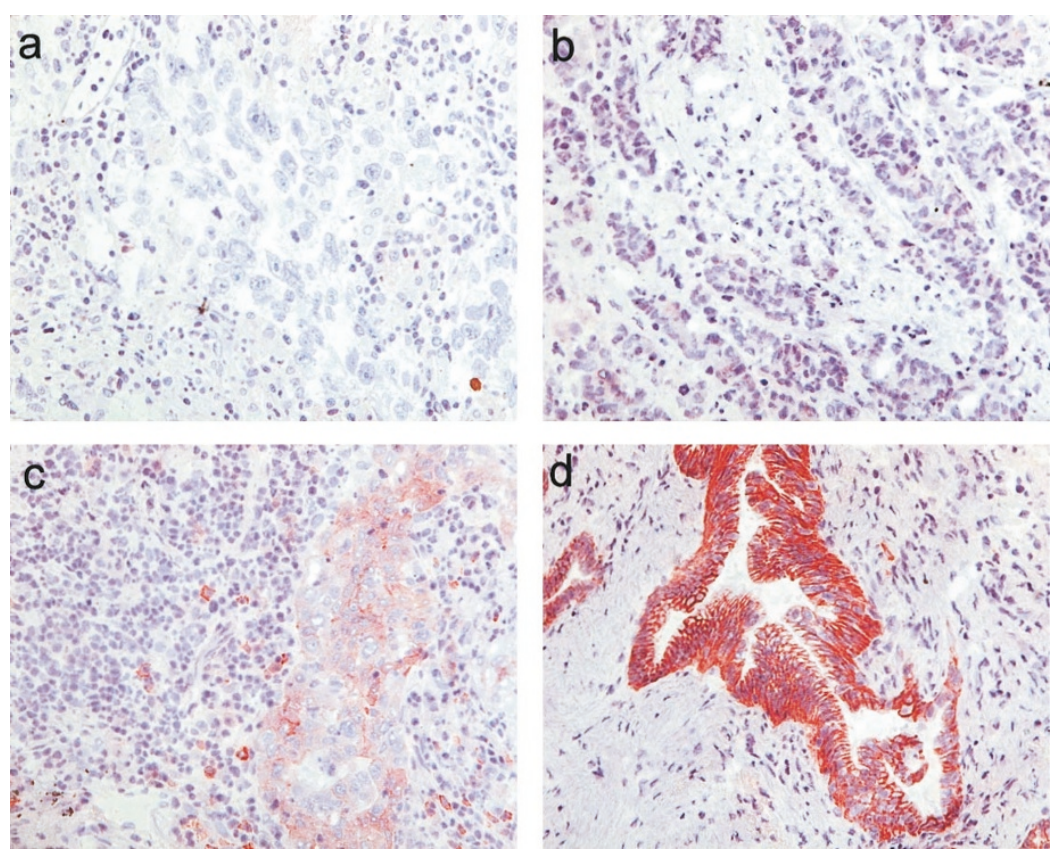

Figure 5.

Immunohistochemical detection of MRP3 in human tumor samples using aminoethyl carbazole as the chromogen (see also Table 2). MRP3 was stained with $\mathrm{M}_{3}$ ll-21. In most of the samples, including intestinal and adrenal adenocarcinoma, MRP3 levels were low or undetectable. Absence of MRP3 is illustrated in a seminoma patient (a) and in a case of small intestine carcinoma (b). (Strong) positive MRP3 staining was observed, for example, in a case of lung cancer (c) and in a case of pancreatic adenocarcinoma (d). 
The highest MRP3 levels were observed in the two PFIC3 patients (Fig. 4h, Patient D and Fig. 4i, Patient E). In these livers, with extensive bile duct proliferation and complete portal bridging fibrosis, both bile ducts and almost all hepatocytes stained strongly positive for MRP3.

\section{MRP3 in Human Tumors}

In a panel of 34 tumors comprising frozen samples of tumors of various histogenetic origins, MRP3 levels were examined by immunohistochemical staining (Table 2). In most of the samples, including seminoma (Fig. 5a), intestinal carcinoma (Fig. 5b), and cortical adrenal adenocarcinoma, MRP3 levels were low or undetectable. However, positive MRP3 staining was observed in a fibrosarcoma sample, a case of gastric adenocarcinoma of the intestinal type, in two lung cancer samples (Fig. 5c), and in a case of ovarian cancer. Particularly high MRP3 levels were observed in a case of pancreatic adenocarcinoma (Fig. 5d).

\section{Discussion}

Recently it was shown that rat mrp3 is capable of transporting the bile salts taurolithocholate-3sulfate, taurochenodeoxycholate-3-sulfate, taurocholate, and glycocholate (Hirohashi et al, 2000). Zeng et al (2000) have reported that human MRP3 transports glycocholate at low affinity but with high capacity and that the protein is unable to transport taurocholate. However, experiments in our laboratories have shown that MRP3 is also capable of transporting taurocholate (N. Zelcer, T. Saeki, P. Borst, unpublished data). These results, together with our immunohistochemical and Western blot analyses for MRP3 of normal and diseased human tissues, suggest a role for this ABC-transporter in the cholehepatic and enterohepatic circulation of bile constituents. Thus, the basolaterally located MRP3 may play a role in the transport of possibly toxic cholephiles, notably bile salts and bilirubin, from the exposed tissue into the bloodstream. In the liver, total MRP3 protein levels were found to be generally low, with clear MRP3 staining in the cholangiocytes but only low MRP3 staining in the basolateral membranes of hepatocytes surrounding the portal tracts (Fig. 4a and Kool et al, 1999). In cholangiocytes, MRP3 may play an important role in handling of bile constituents, because these cells are the first cells that come into contact with high concentrations of these compounds after secretion by the hepatocytes, and these cells can take up bile components, for example, bile salts via the apical sodium-dependent bile salt transporter (ASBT) (Lazaridis et al, 1997).

It was reported that in Dubin Johnson patients, MRP3 is strongly up-regulated (Konig et al, 1999). These patients lack MRP2 in their hepatocanalicular membranes and accumulate organic anions, such as conjugated bilirubin, in their plasma. A similar obser- vation was made in $\mathrm{EHBR}$ and $\mathrm{TR}^{-}$rats, two rat models for this inherited disease (Ito et al, 1997; Paulusma et al, 1996). Thus, accumulation of compounds such as bilirubin may lead to secondary induction of MRP3, allowing basolateral transport into the bloodstream (Ogawa et al, 2000).

Here, in liver samples from various cholestatic patients, we also detected variable, but generally high levels of MRP3. These levels sometimes appeared higher only because of an increased number of cholangiocytes, but most frequently marked upregulation in the proliferative cholangiocytes and variable induction in the hepatocytes was observed. MRP3 levels may be induced in the liver upon cholestatic stress and/or cell damage, thus reflecting a first line cellular defense mechanism. Indeed, in the patients with cholestasis and strong cholangiocyte proliferation, for example, the patient with the Klatskin tumor and the PFIC1 patient (Fig. 4d and 4e), high to very high MRP3 levels were observed in the proliferative bile duct epithelium. Highest levels of MRP3 and localization in the hepatocytes were observed in the two PFIC3 patients (Fig. 4h and 4i). These patients with end-stage liver disease have marked hepatocyte damage because they lack the MDR3 P-gp protein in their hepatocanalicular membranes and are therefore unable to secrete bile salt neutralizing phosphatidylcholine into their bile. In this condition, the biliary tree is not protected from the toxic bile salts. The chronic state of cholestasis in these patients was shown to induce bile duct metaplasia in the hepatocytes. Thus, MRP3 expression may not only be increased because of increased bile duct proliferation, but also because of transformation of hepatocytes into a more bile duct like phenotype.

Our observations on up-regulation of MRP3 in the liver of cholestatic patients show that the process is more diverse and complex than in rats with ligated bile ducts (Hirohashi et al, 1998; Ogawa et al, 2000; Soroka et al, 2001). Like in rats, MRP3 in humans seems to be induced under cholestatic conditions but the expression is much more variable than in rodents. In a hepatitis patient with only mild signs of cholestasis, MRP3 expression was very high, whereas expression was not always high in patients with biliary atresia, who by definition suffer from severe cholestasis (note the characteristic yellow/green bile pigment plugs in Figure 4f). Thus, other factors, such as inflammatory signals, might play a role in the induction of MRP3 expression as well.

A role for MRP3 in reabsorption of bile components in the intestines also seems very likely. Whereas a protective role for MRP3 in the human gallbladder most likely relates to the continuous exposure to bile, the function of MRP3 in the pancreas is less clear. Here, the MRP3-positive duct cells secrete a watery, bicarbonate-rich fluid that flushes digestive enzymes through the ducts and ultimately neutralizes acids within the small intestine. In humans, the main pancreatic duct (generally) joins the main bile duct just before entering the duodenum. Therefore, incidental exposure to bile may occur, and induce up-regulation 
Table 2. MRP3 Staining in Frozen Sections of Human Tumors

\begin{tabular}{lcc}
\hline \multicolumn{1}{c}{ Tumor type } & $n$ & $\begin{array}{c}\text { MRP3 } \\
\text { staining }\end{array}$ \\
\hline Small intestine, adeno carc. & 2 & - \\
Colon, adeno carc. & 2 & - \\
Pancreas, adeno carc. & 1 & +++ \\
Pancreas, adeno carc. & 1 & $+/-$ \\
Adrenal gland, adeno carc. & 2 & - \\
Stomach, stromal type & 1 & - \\
Stomach, epithelial type & 1 & ++ \\
Kidney, Grawitz tumor & 2 & $+/-$ \\
Lung, adeno carc. & 2 & ++ \\
Testis, seminoma & 2 & - \\
Prostate, adeno carc. & 2 & - \\
Bladder, urothelial cell carc. & 2 & - \\
Mamma, adeno carc. & 2 & - \\
Cervical cancer, squamous cell carc. & 2 & - \\
Ovarian cancer, adeno carc. & 1 & + \\
Ovarian cancer, clear cell type & 1 & - \\
Melanoma & 2 & - \\
Round cell sarcoma & 1 & - \\
Fibro sarcoma & 1 & + \\
Neuroblastoma & 2 & - \\
Angiosarcoma & 1 & - \\
Schwannoma & 1 & - \\
\hline n number of & & - \\
\hline
\end{tabular}

n, number of samples; carc., carcinoma; - , no staining; $+/-$, very weak staining; + , weak staining; ++ , positive staining; +++ , strong staining

of local MRP3 protein levels, providing protection of the pancreatic ducts. Compared with the staining pattern observed for MDR1 P-gp, the MRP3 staining is mainly observed in the larger ductules, suggesting their close apposition to the duodenum. The differences in reported MRP3 mRNA levels in the pancreas (Konig et al, 1999; Uchiumi et al, 1998) (see Table 1) may therefore be related to the use of samples from different regions of the pancreas and/or differences in exposure to bile constituents.

The possible roles of MRP3 outside the gastrointestinal tract, in the kidney and adrenal gland, are as yet unclear. In the kidney, MRP3 may also contribute to reabsorption of substrates (ie, from the urine into the blood).

Increasing knowledge of the normal tissue distribution of MRP3, as shown here, should be valuable for appropriate anticipation of lack of chemotherapeutic effects in the treatment of tumors arising from tissues with (high) endogenous MRP3 expression, such as the adrenal gland, the pancreas, and the liver. However, although only a relatively small panel of human tumors was investigated, distinct MRP3 levels were occasionally observed. Interestingly, positive MRP3 staining was observed not only in some tumors originating from MRP3-positive tissues, but also in samples obtained from tissues without detectable endogenous MRP3. In conclusion, analyses of MRP3 levels in larger panels of primary and relapsed tumors may reveal clinical relevance for the optimal design of individualized drug treatment regimens.

\section{Materials and Methods}

\section{Tissues and Tumor Samples}

Normal human tissues and tumor samples were obtained from the tissue bank of the Free University Hospital and the Netherlands Cancer Institute (Amsterdam, the Netherlands). The tissues were acquired from surgical pathology specimens within 2 hours of resection, and autopsy specimens within 12 hours of death. Liver samples of cholestatic patients were from the tissue bank of the Academic Medical Center (Amsterdam, The Netherlands). All samples were snap-frozen and stored in liquid nitrogen until use.

\section{Cholestatic Liver Samples}

Liver samples from patients with moderate to severe cholestasis included:

- Klatskin tumor patient. Pathology: ductular proliferation with fibrosis and inflammation. Enzymes: bilirubin $13 \mu \mathrm{mol} / \mathrm{l}$, aspartate-aminotransferase (ASAT) $71 \mathrm{U} / \mathrm{l}$, alanine-aminotransferase (ALAT) $55 \mathrm{U} / \mathrm{l}$, alkaline phosphatase (AP) $416 \mathrm{U} / \mathrm{l}$, gammaglutamyltransferase (GGT) $602 \mathrm{U} / \mathrm{l}$.

- Hepatitis patient, at 6 months of age. Pathology: intraparenchymal cholestasis with toxic-like hepatitis. Enzymes: bilirubin $28 \mu \mathrm{mol} / \mathrm{l}$, ASAT $103 \mathrm{U} / \mathrm{l}$, ALAT 117 U/I, AP 230 U/l, GGT 84 U/l. Bile salts: $55 \mu \mathrm{mol} / \mathrm{l}$.

- Atresia patient (Patient A), at 10 weeks of age. Pathology: severe biliary fibrosis and cholestasis. Enzymes: bilirubin $172 \mu \mathrm{mol} / \mathrm{l}$, ASAT $184 \mathrm{U} / \mathrm{l}$, ALAT 189 U/I, AP 980 U/I, GGT 1119 U/I.

- Atresia patient (Patient B), at 8 weeks of age. Pathology: extensive cholestasis, ductal proliferation, biliary fibrosis. Enzymes: bilirubin $196 \mu \mathrm{mol} / \mathrm{l}$, ASAT 357 U/l, ALAT 256 U/I, AP 780 U/l, GGT 647 U/l. Bile salts: $510 \mu \mathrm{mol} / \mathrm{l}$.

- Atresia patient (Patient C), at 8 weeks of age. Pathology: cholestasis, ductal proliferation, biliary fibrosis. Enzymes: bilirubin $244 \mu \mathrm{mol} / \mathrm{l}$, ASAT $462 \mathrm{U} / \mathrm{l}$, ALAT 245 U/l, AP 865 U/I, GGT 550 U/l. Bile salts: 137 $\mu \mathrm{mol} / \mathrm{l}$.

- PFIC1 patient, absence of FIC1, a P-type ATPase of unknown function, which probably plays a role in the enterohepatic bile salt circulation. Pathology: endstage liver cirrhosis.

- PFIC2 patient, common European mutation in bile salt efflux pump (BSEP, sister of P-gp [sP-gp], $A B C B 11)$. Pathology: cholestasis, fibrosis, ductopenia. Enzymes: bilirubin $54 \mu \mathrm{mol} / \mathrm{l}$, ASAT $222 \mathrm{U} / \mathrm{l}$, ALAT 242 U/I, AP 401 U/I, GGT 38 U/l. Bile salts: high.

- PFIC3 patient (Patient D), missense mutation in transmembrane span 6 in MDR3 P-gp (ABCB4). Pathology: end-stage liver cirrhosis with cholestasis, ductular proliferation, onion skill fibrosis with complete portal bridging. Enzymes: bilirubin $58 \mu \mathrm{mol} / \mathrm{l}$, AP 749 U/I, GGT 250 U/l. Bile salts: $401 \mu \mathrm{mol} / \mathrm{l}$.

- PFIC3 patient (Patient E), 7 base pair deletion with frameshift in transmembrane span 2 and truncation in MDR3 P-gp. Pathology: end-stage liver cirrhosis with cholestasis, ductular proliferation, onion skill fibrosis with complete portal bridging. Enzymes: bilirubin 36 
$\mu \mathrm{mol} / \mathrm{l}$, AP 876 U/I, GGT 274 U/l. Bile salts: 300 $\mu \mathrm{mol} / \mathrm{l}$.

Average normal values: bilirubin $17 \mu \mathrm{mol} / \mathrm{l}$, ASAT $<25$ U/I, ALAT <30 U/I, AP 25-100 U//, GGT <40 U/l.

\section{Antibodies}

The C219 monoclonal antibody (Mab) was purchased from Alexis (San Diego, California) and used in the recommended dilution. MDR1 P-gp detection was with JSB-1 and C219 Mab; MRP1 detection was with MRPr1 and MRPm6; MRP2 detection was with $\mathrm{M}_{2} \mathrm{l}-4$; and $M_{2} I I I-6$ and MRP3 detection was with $M_{3} I I-9$ and $M_{3} I l-21$. All Mab are murine Mab, except for MRPr1, which is a rat Mab. The Mab were kept as concentrated supernatants and used in the immunohistochemical stainings in a final concentration of approximately 10 $\mu \mathrm{g} / \mathrm{ml}$. The characteristics of the Mab have been described in detail in reference (Scheffer et al, 2000). Rabbit polyclonal antisera against kidney Tamm-Horsfall protein and aquaporin-2 were a kind gift of Dr. R. A. M. H. van Aubel, University of Nijmegen, The Netherlands.

\section{Western Blots}

Membrane fractions of tissues were isolated by homogenizing the tissue samples $(0.5 \mathrm{~g})$ in $10 \mathrm{ml}$ of lysis buffer at $0^{\circ} \mathrm{C}$, as described previously (Flens et al, 1996). Samples containing 10-40 $\mu \mathrm{g}$ of protein were size-fractionated by SDS/7.5\% PAGE and then transferred onto a nitrocellulose filter by electroblotting. After blotting, the filters were blocked for at least 2 hours in blockbuffer (PBS containing 1\% BSA, 1\% milk powder, and $0.05 \%$ Tween-20), followed by incubation for 2 hours with the primary antibody in blockbuffer. MRP3 protein was detected with mouse Mab $M_{3} I I-9$ or $M_{3}$ Il-21. Immunoreactivity was visualized with peroxidase-conjugated rabbit anti-mouse immunoglobulins (DAKO, Glostrup, Denmark), followed by enhanced chemiluminescence detection (Amersham Pharmacia Biotech, Little Chalfont, United Kingdom).

\section{Immunohistochemistry}

Cytospin preparations and cryosections $(4 \mu \mathrm{m})$ were airdried overnight and fixed for 7 minutes in acetone at room temperature. The slides were incubated with hybridoma supernatant for 1 hour at room temperature, followed by a 1-hour incubation with horseradish peroxidase-labeled rabbit-anti-mouse or -anti-rat serum (1:200; DAKO). Then a 10-minute incubation with fluorescein isothiocyanate-labeled tyramine in PBS containing $0.01 \% \mathrm{H}_{2} \mathrm{O}_{2}$ was performed. The slides were examined under a fluorescence microscope (Leica DMRB, Rijswijk, The Netherlands). To obtain more permanent results and for a better impression of morphology, the slides were further incubated with horseradish peroxidase-labeled rabbit $F\left(a b^{\prime}\right)_{2}$-antifluorescein isothiocyanate fragments (1:100; DAKO). Color development was with $0.4 \mathrm{mg} / \mathrm{ml}$ amino-ethylcarbazole and $0.02 \% \mathrm{H}_{2} \mathrm{O}_{2}$ as a chromogen. Nuclei were counterstained with hematoxylin and the slides were mounted with Kaiser's glycerol gelatin (Merck, Darmstadt, Germany). Negative controls consisted of replacing the primary antibody with irrelevant isotypematched control antibodies.

\section{Acknowledgements}

The authors would like to thank Dr. Rémon A. M. H. van Aubel for providing rabbit polyclonal antisera against kidney Tamm-Horsfall protein and aquaporin-2, Ms. Angelique R. Verlaan for technical assistance, and Mr. Noam Zelcer for critically reading the manuscript.

\section{References}

Belinsky MG, Bain LJ, Balsara BB, Testa JR, and Kruh GD (1998). Characterization of MOAT-C and MOAT-D, new members of the MRP/cMOAT subfamily of transporter proteins. J Natl Cancer Inst 90:1735-1741.

Borst P, Evers R, Kool M, and Wijnholds J (2000). A family of drug transporters: The multidrug resistance-associated proteins. J Natl Cancer Inst 92:1295-1302.

Cole SP, Bhardwaj G, Gerlach JH, Mackie JE, Grant CE, Almquist KC, Stewart AJ, Kurz EU, Duncan AM, and Deeley $R G$ (1992). Overexpression of a transporter gene in a multidrug-resistant human lung cancer cell line. Science 258:1650-1654.

Cole SP and Deeley RG (1998). Multidrug resistance mediated by the ATP-binding cassette transporter protein MRP. Bioessays 20:931-940.

Cui YH, Konig J, Buchholz U, Spring H, Leier I, and Keppler D (1999). Drug resistance and ATP-dependent conjugate transport mediated by the apical multidrug resistance protein, MRP2, permanently expressed in human and canine cells. Mol Pharmacol 55:929-937.

Deen PM, Croes H, van Aubel RA, Ginsel LA, and van Os $\mathrm{CH}$ (1995). Water channels encoded by mutant aquaporin-2 genes in nephrogenic diabetes insipidus are impaired in their cellular routing. J Clin Invest 95:2291-2296.

Evers R, de Haas M, Sparidans R, Beijnen J, Wielinga PR, Lankelma J, and Borst P (2000). Vinblastine and sulfinpyrazone export by the multidrug resistance protein MRP2 is associated with glutathione export. Br J Cancer 83:375-383.

Flens MJ, Zaman GJ, van der Valk P, Izquierdo MA, Schroeijers AB, Scheffer GL, van der Groep P, de Haas M, Meijer CJ, and Scheper RJ (1996). Tissue distribution of the multidrug resistance protein. Am J Path 148:1237-1247.

Hirohashi T, Suzuki H, Ito K, Ogawa K, Kume K, Shimizu T, and Sugiyama $Y$ (1998). Hepatic expression of multidrug resistance-associated protein-like proteins maintained in eisai hyperbilirubinemic rats. Mol Pharmacol 53:1068-1075.

Hirohashi T, Suzuki H, and Sugiyama Y (1999). Characterization of the transport properties of cloned rat multidrug resistance-associated protein 3 (MRP3). J Biol Chem 274: 15181-15185.

Hirohashi T, Suzuki H, Takikawa H, and Sugiyama Y (2000). ATP-dependent transport of bile salts by rat multidrug resistance-associated protein 3 (Mrp3). J Biol Chem 275: 2905-2910. 
Hopper E, Belinsky MG, Zeng H, Tosolini A, Testa JR, and Kruh GD (2001). Analysis of the structure and expression pattern of MRP7 (ABCC10), a new member of the MRP subfamily. Cancer Lett 162:181-191.

Ito $\mathrm{K}$, Suzuki $\mathrm{H}$, Hirohashi $\mathrm{T}$, Kume $\mathrm{K}$, Shimizu T, and Sugiyama $Y$ (1997). Molecular cloning of canalicular multispecific organic anion transporter defective in EHBR. Am J Physiol 272:G16-G22.

Kiuchi Y, Suzuki H, Hirohashi T, Tyson CA, and Sugiyama Y (1998). cDNA cloning and inducible expression of human multidrug resistance associated protein 3 (MRP3). FEBS Lett 433:149-152.

Konig J, Rost D, Cui YH, and Keppler D (1999). Characterization of the human multidrug resistance protein isoform MRP3 localized to the basolateral hepatocyte membrane. Hepatology 29:1156-1163.

Kool M, de Haas M, Scheffer GL, Scheper RJ, van Eijk MJ, Juijn JA, Baas F, and Borst P (1997). Analysis of expression of CMOAT (MRP2), MRP3, MRP4, and MRP5, homologues of the multidrug resistance-associated protein gene (MRP1), in human cancer cell lines. Cancer Res 57:3537-3547.

Kool M, van der Linden M, de Haas M, Scheffer GL, de Vree JML, Smith AJ, Jansen G, Peters GJ, Ponne N, Scheper RJ, Oude Elferink RPJ, Baas F, and Borst P (1999). MRP3, an organic anion transporter able to transport anti-cancer drugs. Proc Natl Acad Sci U S A 96:6914-6919.

Lazaridis KN, Pham L, Tietz P, Marinelli RA, deGroen PC, Levine S, Dawson PA, and LaRusso NF (1997). Rat cholangiocytes absorb bile acids at their apical domain via the ileal sodium-dependent bile acid transporter. J Clin Invest 100: 2714-2721.

Nielsen S, DiGiovanni SR, Christensen El, Knepper MA, and Harris HW (1993). Cellular and subcellular immunolocalization of vasopressin-regulated water channel in rat kidney. Proc Natl Acad Sci U S A 90:11663-11667.

Ogawa K, Suzuki H, Hirohashi T, Ishikawa T, Meier PJ, Hirose K, Akizawa T, Yoshioka M, and Sugiyama Y (2000). Characterization of inducible nature of MRP3 in rat liver. Am J Physiol Gastrointest Liver Physiol 278:G438-G446.

Ortiz DF, Li S, Ivyer R, Zhang X, Novikoff P, and Arias IM (1999). MRP3, a new ATP-binding cassette protein localized to the canalicular domain of the hepatocyte. Am J Physiol 276:1493-1500.
Paulusma CC, Bosma PJ, Zaman GJ, Bakker CT, Otter M, Scheffer GL, Scheper RJ, Borst P, and Oude Elferink RP (1996). Congenital jaundice in rats with a mutation in a multidrug resistance-associated protein gene. Science 271 : 1126-1128.

Scheffer GL, Kool M, Heijn M, de Haas M, Pijnenborg ACLM, Wijnholds J, van Helvoort A, de Jong MC, Hooijberg JH, Mol CAAM, van der Linden M, de Vree JML, van der Valk P, Oude Elferink RPJ, Borst P, and Scheper RJ (2000). Specific detection of multidrug resistance proteins MRP1, MRP2, MRP3, MRP5 and MDR3 P-glycoprotein with a panel of monoclonal antibodies. Cancer Res 60:5269-5277.

Sikri KL, Foster CL, MacHugh N, and Marshall RD (1981). Localization of Tamm-Horsfall glycoprotein in the human kidney using immuno-fluorescence and immuno-electron microscopical techniques. J Anat 132:597-605.

Soroka CJ, Lee JM, Azzaroli F, and Boyer JL (2001). Cellular localization and up-regulation of multidrug resistance- associated protein 3 in hepatocytes and cholangiocytes during obstructive cholestasis in rat liver. Hepatology 33:783-791.

Uchiumi T, Hinoshita E, Haga S, Nakamura T, Tanaka T, Toh S, Furukawa M, Kawabe T, Wada M, Kagotani K, Okumura K, Kohno K, Akiyama S, and Kuwano M (1998). Isolation of a novel human canalicular multispecific organic anion transporter, cMOAT2/MRP3, and its expression in cisplatinresistant cancer cells with decreased ATP-ase-dependent drug transport. Biochem Biophys Res Commun 252:103110.

Young LC, Campling BG, Voskoglou-Nomikos T, Cole SPC, Deeley RG, and Gerlach JH (1999). Expression of multidrug resistance protein-related genes in lung cancer: Correlation with drug response. Clin Cancer Res 5:673-680.

Zeng H, Bain LJ, Belinsky MG, and Kruh GD (1999). Expression of multidrug resistance protein-3 (multispecific organic anion transporter-D) in human embryonic kidney 293 cells confers resistance to anticancer agents. Cancer Res 59: 5964-5967.

Zeng H, Liu G, Rea PA, and Kruh GD (2000). Transport of amphipathic anions by human multidrug resistance protein 3 . Cancer Res 60:4779-4784. 